\title{
Voluntary exercise improves performance of a discrimination task through effects on the striatal dopamine system
}

\author{
Meghan C. Eddy, Katherine J. Stansfield, and John T. Green ${ }^{1}$ \\ Department of Psychology, University of Vermont, Burlington, Vermont 05405-0134, USA
}

\begin{abstract}
We have previously demonstrated that voluntary exercise facilitates discrimination learning in a modified T-maze. There is evidence implicating the dorsolateral striatum (DLS) as the substrate for this task. The present experiments examined whether changes in DLS dopamine receptors might underlie the exercise-associated facilitation. Infusing a DIR antagonist into the DLS prior to discrimination learning facilitated the performance of nonexercising rats but not exercising rats. Infusing a D2R antagonist impaired the performance of exercising rats but not nonexercising rats. Exercise-associated facilitation of this task may rely on an exercise-induced decrease in DIR and increase in D2R activation in the DLS.
\end{abstract}

Executive functions, such as working memory, cognitive flexibility, abstract thinking, and planning (Lezak 1982), are often the targets of research looking at the effects of exercise on human brain function. Meta-analysis of studies engaging older participants (ages 60-85) in exercise intervention programs suggests that exercise can improve several measures of cognition, but that the largest effects are on executive function (Hillman et al. 2008). Set-shifting is a measure of discrimination and cognitive flexibility used in both humans and rodents. Our lab has demonstrated that rats require fewer trials to reach the learning criterion of the initial discrimination phase of a set-shift task following 2 wk of voluntary wheel running (Eddy et al. 2013).

In rodents, the initial discrimination in a set-shift task involves the dorsolateral striatum (DLS) (Palencia and Ragozzino 2005). This suggests that exercise is affecting the DLS in some way. One likely candidate is the dopamine (DA) system. There is abundant evidence that exercise impacts the striatal DA system (Gilliam et al. 1984; MacRae et al. 1987; Fisher et al. 2004; Petzinger et al. 2007; Foley and Fleshner 2008; Gerecke et al. 2010; Vuckovic et al. 2010), but these effects have not been linked to effects on learning. Therefore, the purpose of the current experiments was to test the hypothesis that changes in DLS DA receptors are responsible for our previously observed exercise-associated improvement in DLS-dependent discrimination learning (Eddy et al. 2013). D1 receptors (D1Rs) and D2 receptors (D2Rs) were the focus of these studies, as they are the most highly expressed DA receptors in the striatum (Valjent et al. 2009). As a starting place for this line of research, we used receptor antagonists to block the effects of striatal DA release during our task, with the reasoning that exercising and nonexercising rats would be affected differently.

Male Wistar rats $(n=9-13$ /group) obtained from Harlan Laboratories were used. Rats were between 59- and 63-d old when they arrived in the colony, and were housed individually. Rats assigned to the exercise group were given unlocked running wheels following colony acclimation. Nonexercise animals were given identical wheels that were locked in place to control for environmental enrichment effects. Rats had 24-h ad libitum access

\footnotetext{
'Corresponding author

E-mail john.green@uvm.edu

Article is online at http://www.learnmem.org/cgi/doi/10.1101//m.034462.114.
}

to running wheels for $\sim 18 \mathrm{~d}$ prior to testing. The running wheels (Med Associates Inc.) were $36 \mathrm{~cm}$ in diameter and had an automatic counter attached that recorded every quarter revolution. A cross maze, as previously described (Stefani et al. 2003; Eddy et al. 2013) was used for discrimination training. The four arms varied along two dimensions: brightness and texture. Thus, the arms were black/smooth, black/rough, white/smooth, and white/rough. A gray insert could be positioned between the central platform and any one of the arm entrances to create a T configuration. Between trials, the rats were placed in a gray holding chamber containing animal bedding.

Cannulation surgery took place $\sim 3 \mathrm{~d}$ following the introduction of the running wheel to the home cage. Rats were anesthetized with isoflurane and stereotaxic surgery was performed in order to bilaterally implant guide cannulae (22G, Plastics One) in the dorsolateral striatum. Coordinates used were $+0.2 \mathrm{~mm}$ from bregma, $\pm 3.8 \mathrm{~mm}$ from midline, and $-4.8 \mathrm{~mm}$ ventral from the skull (coordinates from Palencia and Ragozzino 2005). Cannulae placements are shown in Figure 1. Rats were given 5-6 d of recovery from surgery, at which time food restriction began. Once the baseline weight was achieved (typically 5-6 d from start of food restriction), there were $6 \mathrm{~d}$ of habituation to the maze (see Eddy et al. 2013 for details).

Immediately prior to discrimination testing, injection cannulae (28G) were inserted bilaterally into guide cannulae. Injection cannula tips protruded $1 \mathrm{~mm}$ below the guide cannula tip. Each injection cannula was connected to tubing, which was attached to a $10-\mu \mathrm{L}$ glass Hamilton syringe. An infusion of 0.5 $\mu \mathrm{L}$ per side was delivered at a rate of $0.25 \mu \mathrm{L}$ per minute using a microinfusion pump. In Experiment 1, half of the animals received an infusion of saline vehicle and the other half received $1.0 \mu \mathrm{g} / 0.5 \mu \mathrm{L}$ SCH23390 (D1R antagonist) dissolved in saline. In Experiment 2, half of the animals received an infusion of saline vehicle and the other half received $1.0 \mu \mathrm{g} / 0.5 \mu \mathrm{L}$ eticlopride (D2R antagonist) dissolved in saline. Following completion of the infusion, the cannulae were left in place for 1 min to allow diffusion of

\footnotetext{
C 2014 Eddy et al. This article is distributed exclusively by Cold Spring Harbor Laboratory Press for the first 12 months after the full-issue publication date (see http://learnmem.cshlp.org/site/misc/terms.xhtml). After 12 months, it is available under a Creative Commons License (Attribution-NonCommercial 4.0 International), as described at http://creativecommons.org/ licenses/by-nc/4.0/.
} 


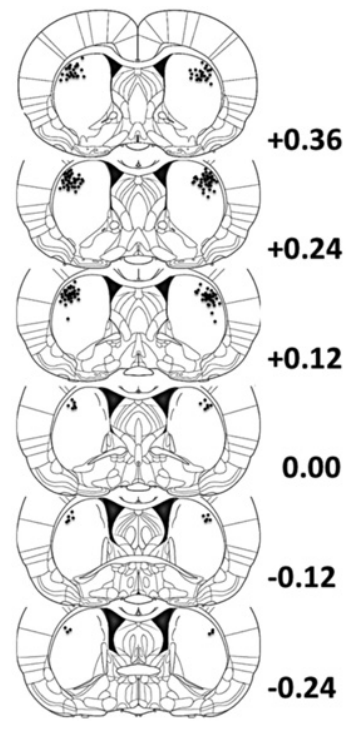

Figure 1. Cannulae placements for Experiments 1 and 2. Numbers on the right go from anterior to bregma (top) to posterior to bregma (bottom). Note that the number of dots does not necessarily represent the total number of cannulae, as there was overlap in several of the placements. (Adapted from Paxinos and Watson [2007] with permission from Elsevier (C) 2007.)

the antagonist or saline. They were then removed, dummy cannulae replaced, and the rats were placed in a transportation container for $5 \mathrm{~min}$ before the start of discrimination testing.

Prior to the discrimination testing session, each group of four rats was randomly assigned to one of the two possible discriminations (white vs. black or rough vs. smooth). Each group of four was assigned to the same stimulus dimension/rewarded arm. Both experiments were completely counterbalanced such that an equal number of rats in each condition were assigned to each stimulus dimension. Additionally, statistical analyses were conducted to ensure that there were no differences between groups of rats assigned to different stimulus dimensions in trials taken to reach criterion.

At the start of testing, the rat was first placed in the holding chamber for $2 \mathrm{~min}$. Next, the rat was placed in the start arm (which was changed for each trial, but was always in the same position in the room), and was allowed to make an arm choice. If the rat chose the rewarded stimulus attribute (correct arm), the rat would find a pellet at the end of the arm and if the rat chose a nonrewarded stimulus attribute (incorrect arm), the rat would not find a pellet. The rat was then removed to the holding chamber for $15 \mathrm{sec}$, the maze was rotated and rebaited, and the rat received another trial. Testing continued until 100 trials were completed. An arm entry was defined as all four paws in contact with the arm. If a rat put two paws into an arm and then turned around and chose the alternate arm, the investigation of the first arm was not considered a committed arm entry because the rat needed to experience the tactile stimuli in order to make an informed arm entry choice. Trials to reach a criterion of eight consecutive correct choices were recorded and served as the dependent measure of learning. In summary, each rat was given access to a running wheel (locked or unlocked) 2-3 d prior to cannulation surgery and had ad libitum access until the experiment was complete (i.e., following discrimination testing). After recovery from surgery ( $\sim 5-6 \mathrm{~d})$, each rat underwent six successive days of maze habituation. The following day, each rat received an infusion of antagonist or vehicle just prior to discrimination testing.
Following testing, animals were sacrificed with an overdose of pentobarbital and transcardially perfused with $0.9 \%$ saline/ $0.1 \%$ heparin followed by $10 \%$ buffered formalin. Cannulae tip placements were marked with small electrolytic lesions $(100 \mu \mathrm{A}$ for $10 \mathrm{sec}$ ) created by insertion of a 000 insect pin into each of the guide cannulae, insulated except for its tip and projecting $1 \mathrm{~mm}$ below the guide cannulae (the same as the infusion cannula). Brains were stored in $10 \%$ buffered formalin for a minimum of $7 \mathrm{~d}$, and then transferred to a solution of $10 \%$ buffered formalin/ $30 \%$ sucrose for several days. Brains were embedded in albumin/ gelatin and sectioned on a cryostat at a thickness of $50 \mu \mathrm{m}$.

Data were analyzed using IBM SPSS version 21 . For both experiments, omnibus ANOVAs were followed up by one-way ANOVAs to evaluate a set of a priori predictions.

In Experiment 1, exercising rats ran an average of $0.53 \mathrm{~km}$ $( \pm 0.13 \mathrm{~km})$ on the first day of wheel access, and ran an average of $2.87 \mathrm{~km}( \pm 0.64 \mathrm{~km})$ on the last day of wheel access. The final wheel count was taken on the test day (prior to antagonist infusion). Bilateral infusion of the D1R antagonist SCH23390 into DLS just prior to discrimination testing facilitated learning (fewer trials to criterion) in nonexercising, but not exercising, rats (Fig. $2 \mathrm{~A}$ ). In Experiment 2, exercising rats ran an average of $0.34 \mathrm{~km}$ $( \pm 0.09 \mathrm{~km})$ on the first day of wheel access, and ran an average of $6.58 \mathrm{~km}( \pm 0.97 \mathrm{~km})$ on the last day of wheel access. Bilateral infusion of the D2R antagonist eticlopride into DLS just prior to discrimination testing impaired learning (more trials to criterion) in exercising, but not nonexercising, rats (Fig. 2B).

For Experiment 1, a 2 (exercise, no exercise) $\times 2$ (D1R antagonist, vehicle) ANOVA revealed a significant main effect of infusion type, $F_{(1,30)}=5.54, P<0.05$, and a significant main effect of exercise, $F_{(1,30)}=5.87, P<0.05$. Three comparisons were then carried out based on a priori predictions: (1) exercising vehicle compared to nonexercising vehicle, (2) nonexercising antagonist compared to nonexercising vehicle, and (3) exercising antagonist compared to exercising vehicle. Exercising vehicle-infused rats reached criterion in significantly fewer trials than nonexercising vehicle-infused rats, $F_{(1,16)}=7.49, P=0.02$, replicating our previously demonstrated facilitated learning effect of exercise on this task (Eddy et al. 2013). Nonexercising D1R antagonist-infused rats reached criterion in significantly fewer trials than nonexercising vehicle-infused rats, $F_{(1,15)}=6.57, P=0.02$. Finally, exercising D1R antagonist-infused rats did not differ significantly in trials to criterion from exercising vehicle-infused rats, $F_{(1,15)}=$ $0.42, P>0.50$. To look for a possible floor effect that could account for the lack of facilitation in exercising D1R antagonistinfused rats compared to exercising vehicle rats, the data were reanalyzed with the learning criterion set at 10 consecutive correct trials instead of eight. Animals that did not reach this criterion were assigned 100 trials (the maximum number allowed). When the data were reanalyzed using this adjusted learning criterion, the same pattern of results was observed.

For Experiment 2, a 2 (exercise, no exercise) $\times 2$ (D2R antagonist, vehicle) ANOVA revealed a significant main effect of exercise, $F_{(1,43)}=5.51, P<0.05$, and a significant main effect of infusion type, $F_{(1,43)}=6.47, P<0.05$. Three comparisons were then carried out based on a priori predictions: (1) exercising vehicle compared to nonexercising vehicle, (2) nonexercising antagonist compared to nonexercising vehicle, and (3) exercising antagonist compared to exercising vehicle. Exercising vehicle-infused rats reached criterion in significantly fewer trials than nonexercising vehicle-infused rats, $F_{(1,21)}=10.12, P=0.006$, again replicating the effects of exercise on this task. Unlike the facilitation effects of a D1R antagonist on nonexercising rats, nonexercising D2R antagonist-infused rats did not differ in trials to criterion from nonexercising vehicle-infused rats, $F_{(1,21)}=0.34, P>0.05$. Also, unlike the effects of a D1R antagonist, exercising D2R 

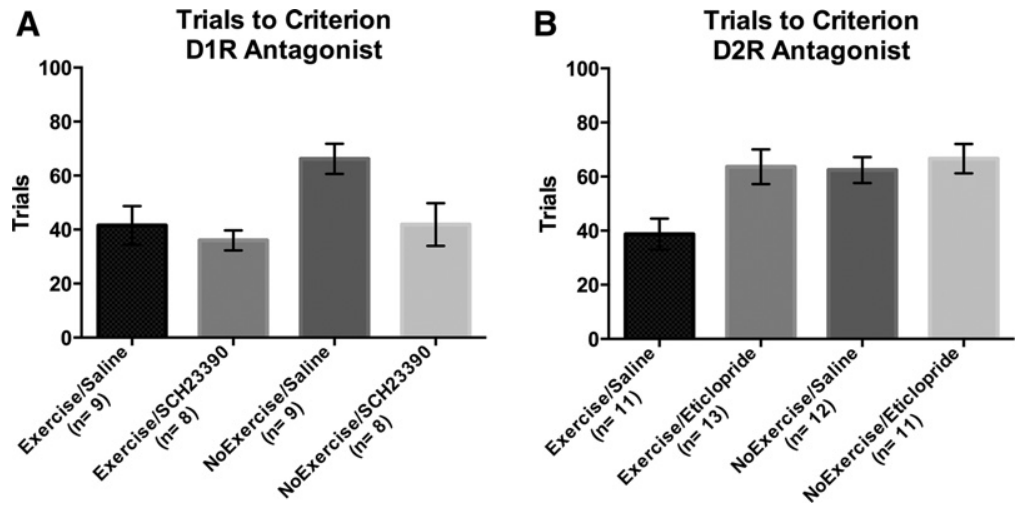

Figure 2. Trials to a criterion of eight consecutive correct arm choices in rats receiving intra-DLS D1R antagonist or vehicle infusions $(A)$ or D2R antagonist or vehicle infusions $(B)$ immediately prior to testing. In the saline-infused groups, exercisers reached criterion in fewer trials than nonexercisers. In the D1R antagonist-infused groups, exercisers showed no effect of infusion, while nonexercising rats receiving antagonist showed improved performance. In the D2R antagonist-infused groups, nonexercisers showed no effect of infusion, while exercising rats receiving antagonist showed impaired performance.

antagonist-infused rats required significantly more trials than exercising vehicle-infused rats to reach criterion, $F_{(1,22)}=7.97, P=$ 0.01 . To look for a possible ceiling effect that could account for the lack of impairment in nonexercising D2R antagonist rats compared to nonexercising vehicle rats, the data were reanalyzed with the learning criterion set at six consecutive correct trials instead of eight. When the data were reanalyzed using this adjusted learning criterion, the same pattern of results was observed.

Time per trial was used as a measure of possible motor effects from the infusions. For Experiment 1, a 2 (exercise, no exercise) $\times$ 2 (D1R antagonist, vehicle) ANOVA revealed a significant main effect of drug, $F_{(1,30)}=6.37, P<0.05$, indicating that D1R antagonist-infused rats (regardless of whether they were exercisers or not) took longer to complete the task (Fig. 3A). For Experiment 2 , the same analysis did not reveal any significant differences between groups (Fig. 3B).

The data suggest that exercise-associated changes in the DLS dopamine system play a role in exercise-associated facilitation in DLS-dependent discrimination learning. Our data showing that antagonizing D2Rs in the DLS selectively impairs learning in rats that have been exercising seem consistent with previous data showing that exercise increases D2R mRNA, protein, and binding in the striatum (Gilliam et al. 1984; MacRae et al. 1987; Fisher et al. 2004; Petzinger et al. 2007; Foley and Fleshner 2008; Vuckovic et al. 2010). Our data are also consistent with a recent study that showed that, with accelerated rotarod training (which bears some resemblance to acquisition of wheel running), there is a shift from reliance on D1Rs and the DMS to reliance on D2Rs and the DLS (Yin et al. 2009). For example, unit recording revealed DMS neurons that increased their firing rate in the early phase of rotarod training (day 1) but not in the late phase (day 8); DLS neurons showed the opposite pattern (Yin et al. 2009). Furthermore, synaptic strength (excitatory postsynaptic potential slope in response to afferent stimulation) was greater in the DMS early in training but greater in the DLS later in
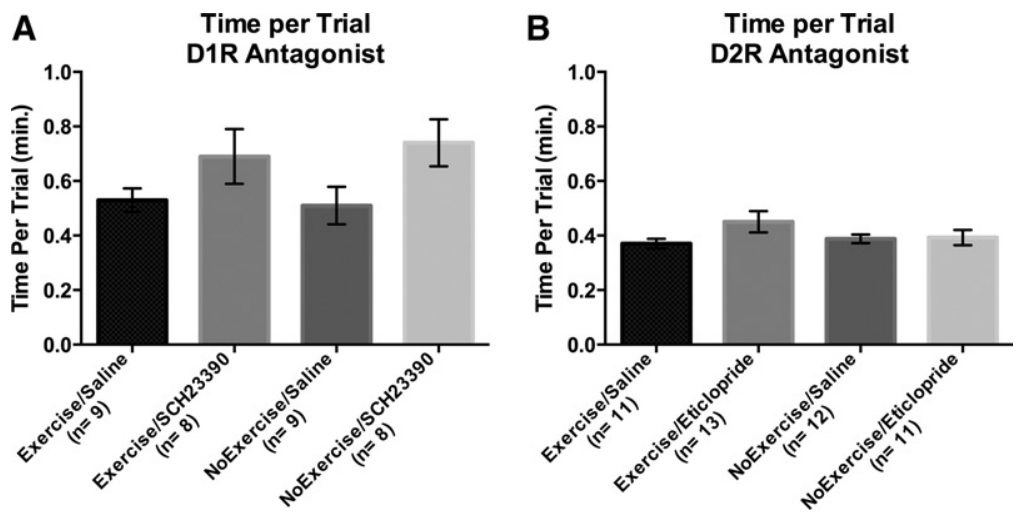

Figure 3. Time per trial in rats receiving intradorsolateral striatum $D 1 R$ antagonist or vehicle infusions $(A)$ or D2R antagonist or vehicle infusions $(B)$ immediately prior to testing. Dorsolateral striatum D1R antagonist infusion slowed performance in exercise and nonexercise groups. Dorsolateral striatum D2R antagonist infusion did not result in any apparent motor effects. 
DA release in the DLS may normally play a role in the early stages of our task, a role that is reduced by exercise. This phasic DA release in the DLS, perhaps generated in response to task-irrelevant stimuli, may compete with phasic DA release in the DMS. Blocking the effect of this phasic DA release on the direct pathway in the DLS by blocking D1Rs facilitates learning by removing competition from the direct pathway in the DMS.

The data presented here add to the expanding research literature demonstrating the positive cognitive effects of physical exercise. Although exercise has many wide-ranging effects on physical, mental, and emotional wellbeing, it is now becoming clearer that it results in specific changes at the chemical, molecular, and systems levels, ultimately modifying behavior. Specifically, our data point to precise changes within the striatal dopamine system, which may be increasing the efficiency and efficacy of this system, and promoting learning enhancements.

\section{Acknowledgments}

This research was supported by funding from NIH/NIMH R01 MH082893. We thank Samantha Luce and Katharine Rifken for their help in data collection.

\section{References}

Bromberg-Martin ES, Matsumoto M, Hikosaka O. 2010. Dopamine in motivational control: rewarding, aversive, and alerting. Neuron 68: $815-834$.

Brown HD, McCutcheon JE, Cone JJ, Ragozzino ME, Roitman MF. 2011. Primary food reward and reward-predictive stimuli evoke different patterns of phasic dopamine signaling throughout the striatum. Eur J Neurosci 34: 1997-2006.

Choi WY, Balsam PD, Horvitz JC. 2005. Extended habit training reduces dopamine mediation of appetitive response expression. J Neurosci $\mathbf{2 5}$ : 6729-6733.

Eddy MC, Rifken KM, Toufexis DJ, Green JT. 2013. Gonadal hormones and voluntary exercise interact to improve discrimination ability in a set-shift task. Behav Neurosci 127: 744-754.

Fisher BE, Petzinger GM, Nixon K, Hogg E, Bremmer S, Meshul CK, Jakowec MW. 2004. Exercise-induced behavioral recovery and neuroplasticity in the 1-methyl-4-phenyl-1,2,3,6-tetrahydropyridinelesioned mouse basal ganglia. J Neurosci Res 77: 378-390.
Foley TE, Fleshner M. 2008. Neuroplasticity of dopamine circuits after exercise: implications for central fatigue. Neuromolecular Med 10: $67-80$.

Gerecke KM, Jiao Y, Pani A, Pagala V, Smeyne RJ. 2010. Exercise protects against MPTP-induced neurotoxicity in mice. Brain Res 1341: $72-83$.

Gilliam PE, Spirduso WW, Martin TP, Walters TJ, Wilcox RE, Farrar RP. 1984. The effects of exercise training on $\left[{ }^{3} \mathrm{H}\right]$-spiperone binding in rat striatum. Pharmacol Biochem Behav 10: 863-867.

Hillman CH, Erickson KI, Kramer AF. 2008. Be smart, exercise your heart: exercise effects on brain and cognition. Nat Rev Neurosci 9: 58-65.

Lezak MD. 1982. The problem of assessing executive functions. Int J Psychol 17: 281-297.

MacRae PG, Spirduso WW, Walters TJ, Farrar RP, Wilcox RE. 1987. Endurance training effects on striatal D2 dopamine receptor binding and striatal dopamine metabolites in presenescent older rats. Psychopharmacology 92: 236-240.

Palencia CA, Ragozzino ME. 2005. The contribution of NMDA receptors in the dorsolateral striatum to egocentric response learning. Behav Neurosci 119: 953-960.

Paxinos G, Watson C. 2007. The rat brain in stereotaxic coordinates, 6 th ed. Academic Press, Sydney, New South Wales, Australia.

Petzinger GM, Walsh JP, Akopian G, Hogg E, Abernathy A, Arevalo P, Turnquist P, Vucković M, Fisher BE, Togasaki DM, et al. 2007. Effects of treadmill exercise on dopaminergic transmission in the 1-methyl-4phenyl-1,2,3,6-tetrahydropyridine-lesioned mouse model of basal ganglia injury. J Neurosci 27: 5291-5300.

Richfield EK, Penney JB, Young AB. 1989. Anatomical and affinity state comparisons between dopamine $\mathrm{D} 1$ and $\mathrm{D} 2$ receptors in the rat central nervous system. Neuroscience 30: 767-777.

Schulz W. 2007. Multiple dopamine functions at different time courses. Annu Rev Neurosci 30: 259-288.

Stefani MR, Groth K, Moghaddam B. 2003. Glutamate receptors in the rat medial prefrontal cortex regulate set-shifting ability. Behav Neurosci 117: $728-737$.

Valjent E, Bertrain-Gonzalez J, Herve D, Fisone G, Girault J-A. 2009. Looking BAC at striatal signaling: cell-specific analysis in new transgenic mice. Trends Neurosci 32: 538-547.

Vuckovic MG, Li Q, Fisher B, Nacca A, Leahy RM, Walsh JP, Mukherjee J, Williams C, Jakowec MW, Petzinger GM. 2010. Exercise elevates dopamine D2 receptor in a mouse model of Parkinson's disease: in vivo imaging with [ $\left.{ }^{18} \mathrm{~F}\right]$ fallypride. Mov Disord 25: 2777-2784.

Yin HH, Mulcare SP, Hilario MRF, Clouse E, Holloway T, Davis MI, Hansson AC, Lovinger DM, Costa RM. 2009. Dynamic reorganization of striatal circuits during the acquisition and consolidation of a skill. Nat Neurosci 12: 333-341.

Received January 14, 2014; accepted in revised form March 21, 2014. 


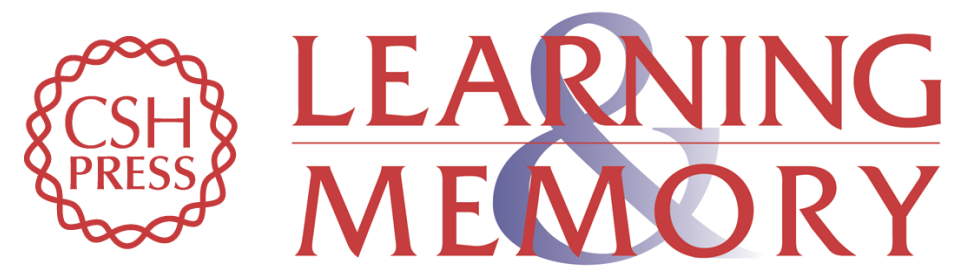

\title{
Voluntary exercise improves performance of a discrimination task through effects on the striatal dopamine system
}

\author{
Meghan C. Eddy, Katherine J. Stansfield and John T. Green
}

Learn. Mem. 2014, 21:

Access the most recent version at doi:10.1101/lm.034462.114

\begin{aligned} & \hline References $\begin{array}{l}\text { This article cites } 19 \text { articles, } 2 \text { of which can be accessed free at: } \\ \text { http://learnmem.cshlp.org/content/21/7/334.full.html\#ref-list-1 }\end{array} \\ & \begin{array}{r}\text { Creative } \\ \text { Commons } \\ \text { License }\end{array} \begin{array}{l}\text { This article is distributed exclusively by Cold Spring Harbor Laboratory Press for the } \\ \text { first } 12 \text { months after the full-issue publication date (see } \\ \text { http://learnmem.cshlp.org/site/misc/terms.xhtml). After } 12 \text { months, it is available under } \\ \text { a Creative Commons License (Attribution-NonCommercial } 4.0 \text { International), as } \\ \text { described at http://creativecommons.org/licenses/by-nc/4.0/. }\end{array} \\ & \begin{array}{c}\text { Receive free email alerts when new articles cite this article - sign up in the box at the } \\ \text { top right corner of the article or click here. }\end{array} \\ &$ Service \end{aligned}

